\begin{tabular}{c} 
Brazilian Journal \\
of Chemical \\
Engineering \\
\hline
\end{tabular}

ISSN 0104-6632

Printed in Brazil

www.abeq.org.br/bjche

Vol. 32, No. 02, pp. 367 - 376, April - June, 2015

dx.doi.org/10.1590/0104-6632.20150322s00003525

\title{
PERFORMANCE OF LOOFA-IMMOBILIZED Rhizopus oryzae IN THE ENZYMATIC PRODUCTION OF BIODIESEL WITH USE OF OLEIC ACID IN $n$-HEXANE MEDIUM
}

\author{
S. Sattari, F. Vahabzadeh* and H. K. Aghtaei \\ Food and Biotechnology Group, Department of Chemical Engineering, Amirkabir University \\ of Technology (Tehran Polytechnic), 424 Hafez Ave, 15875-4413, Tehran, Iran. \\ Phone: + 9821 64543161, Fax: +98 2166405847 \\ E-mail: far@aut.ac.ir
}

(Submitted: May 26, 2014 ; Revised: September 29, 2014 ; Accepted: October 13, 2014)

\begin{abstract}
The performance of loofa-immobilized Rhizopus oryzae (as a whole-cell biocatalyst) in the synthesis of methyl oleate was evaluated using oleic acid as a model substrate. The activities of the cell-bound lipase in terms of the esterification and hydrolysis reactions were found to be higher for the immobilized cells as compared with those of the free cells. The time to reach equilibrium for methyl oleate synthesis was $12 \mathrm{~h}$ in the presence of $n$-hexane (hexane:oleic acid ratio $9: 1(\mathrm{v} / \mathrm{v})$ ), and the yield was $80 \%$. In the absence of solvent, equilibrium was reached after $48 \mathrm{~h}$ and the yield was only $30 \%$. The moisture repellency and the hydrophilic properties of loofa sponge make this natural fiber a good candidate for cell-enzyme immobilization, especially for lipases as the interfacial enzyme.

Keywords: Rhizopus oryzae; Cell-bound lipases; Loofa sponge; Methyl oleate; $n$-hexane.
\end{abstract}

\section{INTRODUCTION}

Concerns over the crude oil shortage and the increasing market price of fossil fuels have generated interest in the production of biodiesel over petrodiesel; moreover, biodiesel is considered an ecofriendly product. The use of vegetable oils for operating a small diesel engine has long been recognized; and by replacing the glycerol present in vegetable oil with methanol or ethanol via a transesterification reaction, the system's viscosity is reduced (Al-Zuhair, 2006). The requirements of the starting materials necessary to produce biodiesel indicate the important role of using dehydrated vegetable oils as well as anhydrous alkaline catalysts. The presence of a higher content of free fatty acids (FFAs) in the lipidic substrate starting material necessitates the introduction of a washing step to remove soaps that form, increas- ing the economic burden of the process (Fjerbaek et al., 2009; Andreani and Rocha, 2012). In the last decade, great attention has been directed towards the enzymatic transesterification process, and lipases have been the focus of almost all of this research (Fukuda et al., 2001; Hama et al., 2006; Bajaj et al., 2010).

The catalytic function of lipases (triacylglycerol hydrolases, EC. 3.1.1.3) is described in terms of their hydrolytic action on carboxylic esters in aqueous media; conversely, in organic solvent, the synthetic role of lipases to acylate the alcohol with a carboxylic acid prevails (Rehm et al., 2010). Lipases act at the oil-water interface, and the negative effect of this interfacial tension is reduced owing to the complex structure of the enzyme in which an amphiphilic domain covers the active site in solution; the mobility of this part of the protein (named the lid) causes

*To whom correspondence should be addressed 
the active site to become exposed to the oily substrate (Schmid et al., 1998). The use of a purified lipase is a real barrier for the enzymatic industrialization of biodiesel; and this process limitation could be reduced by directly using lipase-producing microorganisms, known as a whole-cell biocatalyst. The whole-cell biocatalyst includes the cell wall- or the cell membrane-bound lipase (i.e., intracellular enzyme), which can be used instead of extracellular lipase that requires extraction and purification from the microorganism culture medium (Jin et al., 2009). Studies using whole-cell biocatalysts have mainly focused on the lipase-producing fungus Rhizopus oryzae immobilized on polyurethane foam(Hama et al., 2006; Li et al., 2008). Different immobilization techniques have been practiced in various fermentation processes, and the preference of cell adhesion to a surface compared with cell entrapment in a matrix apparently is due to the simplicity of cell attachment and the lower extent of mass transfer effects of the former (Ogbonna et al., 1994). The cell support selected for immobilization processes should be nonreactive and nontoxic, and the immobilization procedure should be easy to perform; in addition, the support should be mechanically strong enough to withstand long-term usage (Liu et al., 1998). Considering the concept of immobilization used by Atkinson et al. (1979), it has become possible to use particles of any size and porosity for the immobilization of microbial cells. These particles are known as Biomass Support Particles(BSPs). However, the experimental findings reported by the Fukuda group showed that a significant decrease of the membrane-bound lipase secretion into the culture medium was due to the use of polyurethane-immobilized $R$. oryzae (Hama et al., 2006).

Loofa sponge (Luffa cylindrica) has been successfully used for the immobilization of diverse types of cells, including fungi, yeast, microalgae, bacteria, plants, and human and rat hepatocytes (Saeed and Iqbal, 2013). The main components of loofa and other natural fibers are cellulose, lignin, and hemicelluloses, which provide different properties and contribute to the overall characteristics of these materials. In addition, these lignocellulosic materials can be used to position or fix an item of interest such as living cells (Siqueira et al., 2010). Other physical characteristics of the loofa sponge, including its density, porosity, and specific pore volume, further qualify it as a biosupport (Ogbonna et al., 1994). Thus, the physicochemical properties of loofa make it an ideal eco-friendly biosupport.

Regarding the economics of biodiesel production, the use of refined vegetable oils puts further limita- tions on its commercialization. The process has been directed towards the use of waste oils with a high FFA content as a low-cost starting material (Zhang et al., 2003; Silva et al., 2012). Moreover, a model substrate instead of vegetable oil has been used to follow the enzymatic production of biodiesel (Li et $a l ., 2008)$. The aim of the present study was to evaluate the behavior of loofa-immobilized $R$. oryzae in the formation of biodiesel using oleic acid as a model substrate. The test process was monitored in $n$-hexane medium in terms of the cell tolerance towards methanol as the alcoholic substrate. In addition, with use of molecular sieves ( $3 \AA$ ), the capacity of the test system in response to the presence of water was determined. The cell's ability to be used sequentially in the process of biodiesel production was also tested. Finally, comparisons were made with the enzymatic reaction carried out in a solvent-free system.

\section{MATERIALS AND METHODS}

\section{Materials}

All chemicals were of analytical grade and purchased from the local market: oleic acid (Rankem, India), isooctane (Carlo Erba, Italy), and polypeptone (Liofilchem, Italy). The other chemicals used in the present study were from Merck (Germany) and also were obtained from local suppliers.

The loofa sponge used in this study as the cell support was obtained from the mature dried fruit of Luffa cylindrica from Gilan province, Iran. For experimental use, the sponge was cut into segments, which were then cut into circular discs of $15 \mathrm{~mm}$ in diameter and 2-4 $\mathrm{mm}$ in height. The loofa discs were soaked in boiling distilled water for $1 \mathrm{~h}$, with the water being replaced every $15 \mathrm{~min}$. Next, the loofa sponge discs were dried in a laboratory oven $\left(50^{\circ} \mathrm{C}\right)$ (WTC Binder, Germany) before being used for cell immobilization and further experiments.

\section{Microorganism Cultivation and Inoculum Prepa- ration}

Rhizopus oryzae (PTCC5174) was purchased from the Iranian Research Organization for Science and Technology (IROST). The composition of the maintenance medium was $4 \%$ potato dextrose agar plus $2 \%$ nutrient agar. The cultures prepared with the use of this maintenance medium (culture slants) were stored in the refrigerator, and subcultures were routinely made every month using the stock culture. The culture prepared by transfer from the maintenance 
medium was incubated for 7 days under static conditions at $24{ }^{\circ} \mathrm{C}$. From the grown culture, the spore suspension of $R$. oryzae was prepared. Next, each of the agar slants was washed with a small amount of sterile water, and the content on the slant was filtered to separate the filamentous part of the grown culture. Using a hemocytometer, the quantity of spores from the filtrate was determined (Jones et al., 1992). Dilution of the prepared spore suspension was performed as needed to provide a constant quantity of spores $\left(5 \times 10^{8}\right.$ spores $\left.\mathrm{L}^{-1}\right)$ to be used in each experiment.

\section{Preparation of Loofa-Immobilized $R$. oryzae Cells (LICs)}

The basal medium (BSM) contained the following ingredients $\left(\mathrm{g} \mathrm{L}^{-1}\right)$ : polypeptone, $70 ; \mathrm{NaNO}_{3}, 1$; $\mathrm{KH}_{2} \mathrm{PO}_{4}, 1: \mathrm{MgSO}_{4} \cdot 7 \mathrm{H}_{2} \mathrm{O}$, 0.5; olive oil, 30 (Hama et al., 2006). The initial $\mathrm{pH}$ of the BSM was adjusted to 5.6 using $0.5 \mathrm{M} \mathrm{H}_{2} \mathrm{SO}_{4}$. The loofa pieces were weighed and six of them weighing about $0.35 \mathrm{~g}$ were placed in a $250-\mathrm{mL}$ Erlenmeyer flask containing $50 \mathrm{~mL}$ of BSM. These flasks were sterilized in an autoclave $\left(20 \mathrm{~min}\right.$ at $121{ }^{\circ} \mathrm{C}$ ), and the content of the flasks having loofa pieces was inoculated with $0.5 \mathrm{~mL}$ of the spore suspension. The flasks were then incubated at $30^{\circ} \mathrm{C}$ in a shaker incubator $(150 \mathrm{rpm}$ for $24-96 \mathrm{~h}$; Heidolph, Germany). A flask with no loofa pieces was used as the sample of free cells, and the inoculation and incubation procedures described for the LICs were carried out similarly on this sample. The cells grown on the loofa pieces (LICs) were separated using a Buchner vacuum filtration unit and filter paper (Whatman No. 1). The separated cells were washed with distilled water for 1 min, followed by acetone for $5 \mathrm{~min}$ to further remove impurities including adherent oils and fatty acids (Hama et al., 2006). The LICs were dried in a vacuum oven (Ehret, Germany) at 600 mbar. The moisture content of the LICs was determined by a Moisture Balance (Adam Equipment, UK), and the dried LICs with less than $5 \%$ moisture content were used in the experiments. By measuring the weight differences between the LICs and the bare loofa pieces, the amount of biomass of each LIC piece was determined to be approximately $146 \mathrm{mg}$.

\section{Analytical Methods}

\section{Determination of Oleic Acid Content}

The oleic acid concentration was determined according to the spectrophotometric method (spectrophotometer: JASCO, Japan) described by Kwon and
Rhee (1986), which is the modified procedure of the Lowry and Tinsley (1976) colorimetric technique used to quantify the FFA content of a test sample.

\section{Determination of Esterification Activity of LIC Lipase}

The following procedure was used to measure spectrophotometrically $\left(\lambda_{\max }=715 \mathrm{~nm}\right)$ the esterification activity of LIC lipase (Kwon and Rhee, 1986). First, $2 \mathrm{~mL}$ of hexane containing $2 \mathrm{mmol}$ of $n$-butanol and $2 \mathrm{mmol}$ of oleic acid were transferred to a 10-mL screw-capped bottle. Next, one piece of LIC was placed in the bottle to initiate the esterification between $n$-butanol and oleic acid, and the test bottle was incubated in a shaker incubator $\left(38^{\circ} \mathrm{C}, 250 \mathrm{rpm}\right.$ for $1 \mathrm{~h}$ ). The same procedure was applied to the free cell samples. One unit of enzyme activity (U) was defined as the consumption of $1 \mu \mathrm{mol}$ of FFA in this esterification reaction in $1 \mathrm{~min}$ (Hama et al., 2006). A blank sample with all of the necessary ingredients except for the test enzyme (e.g., LIC piece) was also prepared and used in this determination.

\section{Measurement of Hydrolytic Activity of LIC Lipase}

The titration method was used to determine the hydrolytic activity of the LIC lipase. A $50-\mathrm{mL}$ screwcapped bottle containing $2 \mathrm{~g}$ of olive oil, $9 \mathrm{~mL}$ of $0.1 \mathrm{M}$ acetate buffer (pH 5.6), and $1 \mathrm{~mL}$ of $0.05 \mathrm{M} \mathrm{CaCl}_{2}$ was placed in a shaker incubator $\left(30^{\circ} \mathrm{C}, 250 \mathrm{rpm}\right)$. The reaction was initiated by placing one LIC piece in the test bottle. After 15 min, the hydrolytic reaction was terminated by the addition of $40 \mathrm{~mL}$ of $99.5 \%$ ethanol. Thereafter, the FFA titration using $0.1 \mathrm{M} \mathrm{NaOH}$ was performed (Hama et al., 2006). The intracellular hydrolytic activity was determined by defining the activity (U) as the production of $1 \mu \mathrm{mol}$ of FFA in $1 \mathrm{~min}$. The reaction proceeded with the use of $1 \mathrm{~mL}$ of culture broth instead of one LIC piece, and the extracellular hydrolytic activity was measured according to the above-described titration method. The control sample having all of the necessary ingredients except for the LIC pieces was used in this determination.

\section{Determination of Methyl Oleate Yield}

The following procedure was performed to measure the methyl oleate yield either in the presence or absence of solvent. The latter experiment, called test reaction $\mathrm{A}$, was performed by placing oleic acid and methanol as the reaction substrates in a 1:1 molar ratio in a total volume of $3 \mathrm{~mL}$ in a $20-\mathrm{mL}$ screw- 
capped bottle and then adding two LIC pieces to the test bottle. The test solution was incubated in an incubator at $30{ }^{\circ} \mathrm{C}$ and $150 \mathrm{rpm}$. When the methanol substrate was added stepwise, the two other ratios (mol:mol) of oleic acid:methanol used were 1:2 and 1:3.

By some small changes in the above-described experiments, the effect of the solvent on the methyl oleate yield was examined. For instance, test reaction A was prepared by placing $15 \mathrm{~mL}$ of a mixture of oleic acid, methanol, and $n$-hexanein varying amounts, instead of $3 \mathrm{~mL}$, and the reaction was monitored as described above.

The influence of higher concentrations of methanol substrate on the reaction behavior was also determined in the experiments performed in the presence of solvent (the experimental details are presented in the next section and the relevant figures). In addition, a reaction mixture control was prepared without the LIC biocatalyst. The following expression (Eq. (1)) was used to calculate the ester yield:

Ester Yield $(\%)=\frac{\text { FFA }_{\text {Control }}-\text { FFA }_{\text {Test }}}{\text { FFA }_{\text {Control }}} \times 100$

where FFA contents were specified as the test system and the control, respectively.

\section{Addition of Molecular Sieves to the Test System}

Molecular sieves ( $3 \AA$ ) were first placed in a muffle furnace (Nabertherm, Germany) at $230{ }^{\circ} \mathrm{C}$ for $3 \mathrm{~h}$, and the sample was then cooled to ambient temperature. Different amounts of the heat-treated molecular sieves were added to the reaction mixture.

\section{Reusability Capacity of LICs}

The capacity of the LICs to be used consecutively was also studied. After each test reaction (after $12 \mathrm{~h}$ and $48 \mathrm{~h}$ either in the presence or absence of $n$-hexane), the reaction content of the test flask was drained for further analysis, while the LIC pieces were washed with hexane for $30 \mathrm{~min}$. A new reaction mixture was placed in the test flask with the hexanewashed LIC piece(s), and the reaction was monitored as described above.

\section{Data Analysis}

All experiments were carried out in duplicate, and the mean value \pm standard deviation is reported in each case. Connected boxplots were used in some cases to show the central tendency and the variability of the data.

\section{RESULTS AND DISCUSSION}

\section{Loofa-Immobilized $R$. oryzae Cell Behavior and Lipase Expression}

The presence of two types of lipases with different molecular mass values in $R$. oryzae has been reported in the literature, and the one with a lower molecular mass, located in the cell membrane, was found to be readily released in the suspended cell culture (Hama et al., 2006). These findings also showed a considerable decrease in the extent of lipase release upon cell immobilization with the use of polyurethane foam as the cell support. In this context, it has been pointed out that the relationship between lipase release and cell morphology is dependent on the cell type and the enzyme characteristics (Fukuda et al., 2008). In the present study, comparisons were made between the amounts of biomass produced by the free and loofa-immobilized cells of $R$. oryzae, and the changes of the biomass trends for these two types of cells during cultivation ( $96 \mathrm{~h}$ ) are shown in Figure 1(a). After $48 \mathrm{~h}$, the increase of the cell mass for the both cell systems was approximately 2-2.5 times higher than the values obtained within the first $24 \mathrm{~h}$. The lipase activities in terms of esterification and hydrolytic reactions were found to be different for the free and immobilized cells of $R$. oryzae, as shown in Figure $1(\mathrm{~b}-\mathrm{d})$. Expression of the cell-bound lipases in terms of the lipase esterification (known as intracellular lipase) activities at $48 \mathrm{~h}$ for the immobilized and the free cells were $0.13 \mathrm{U} \mathrm{mg}^{-1}$ and $0.03 \mathrm{U} \mathrm{mg}^{-1}$, respectively (Figure $1(\mathrm{~b})$ ). The esterification activity tended to decrease after $48 \mathrm{~h}$, and the percentages of the decrease were $38 \%$ and $73 \%$ for the immobilized and free cells, respectively. The intracellularly produced lipase also possessed hydrolytic activity, and this activity was higher for the LICs compared to that of the free fungal cells (Figure 1(c)). In addition, the extracellularly produced lipase had lipolytic activity, and this activity was higher for the free cells than for the LICs, as shown in Figure 1(d). These results were in agreement with the findings reported for the use of BSPs by the Fukuda research group (Hama et al., 2006), confirming a low lipolytic activity for the extracellularly produced lipase of $R$. oryzae cells upon immobilization. These findings are indicative of the favorable characteristics of loofa sponge as the cell support, and this approach appears to be reasonable, when one considers the constituents of this natural biomaterial along with the active site of lipase having both hydrophilic and hydrophobic components. 

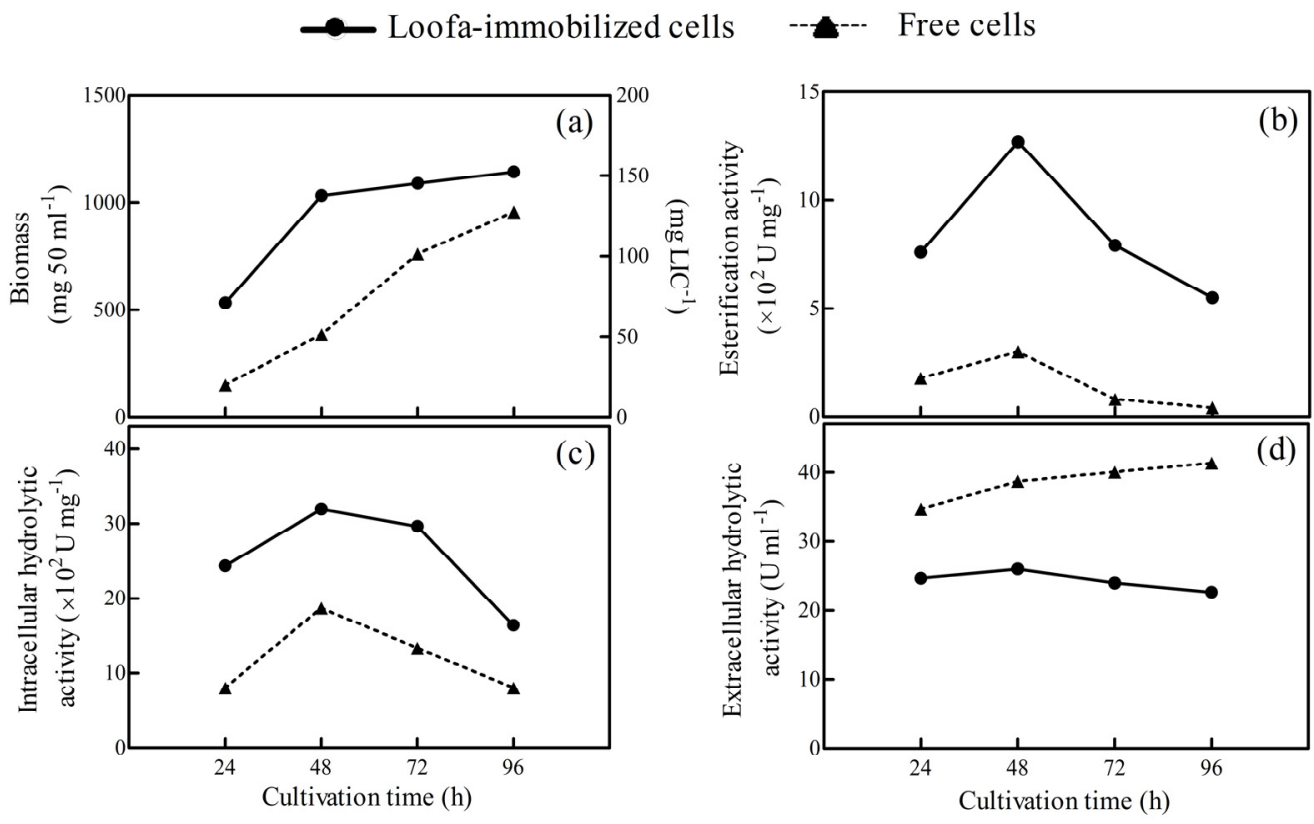

Figure 1: Characteristics of loofa-immobilized $R$. oryzae cells for the production of cell-bound lipases during cultivation: (a) amount of biomass formed; (b) esterification activity; (c) intracellular hydrolytic activity; and (d) extracellular hydrolytic activity.

Curves of methyl oleate yield versus reaction time with different numbers of LIC pieces used in the relevant experiments are presented in Figure 2. The percent conversion at equilibrium was comparable for two to four LIC pieces with the methanol and oleic acid substrates at a 1:1 molar ratio in the presence of $n$-hexane. For 2-4 LIC pieces, the reaction equilibrium was established within $12 \mathrm{~h}$, corresponding to an $80 \%$ conversion. Enzymatic reactions ultimately reach a plateau, indicative of catalytic site saturation by substrate(s). Moreover, in reactions that occur in nonaqueous media, the effects of mass transfer limitations on the reaction kinetics are considerable. In the present study, these effects put more restrictions on the reaction when fewer LIC pieces were used (Figure 2 ). The methyl ester yields obtained after a reaction time of $24 \mathrm{~h}$ were used to present the connected box plot (inset). These data confirm the preference of using two loofa pieces in the synthesis because less variation and more uniformity were demonstrated.

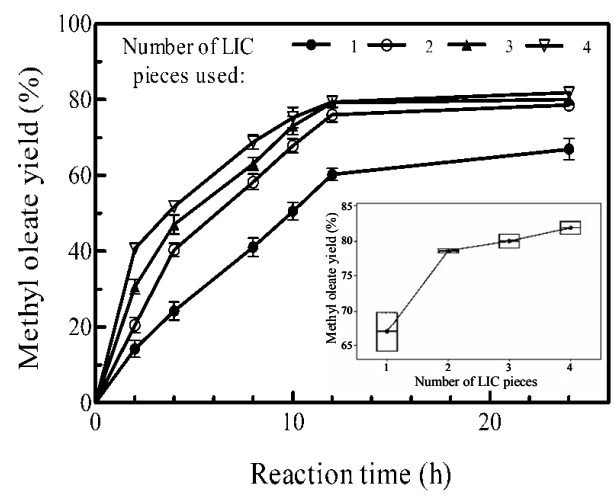

Figure 2: Effect of the number of LIC pieces on methyl oleate production. The biomass content of each LIC piece was approximately $146 \mathrm{mg}$ (see the Materials and Methods section for details). The connected boxplot is shown in the inset. The following experimental conditions were used: molar ratio of methanol:oleic acid, 1:1; incubation temperature, $30^{\circ} \mathrm{C}$; agitation rate, $150 \mathrm{rpm}$; and hexane:oleic acid ratio, 9:1 (v/v). 


\section{LIC Performance Under the Influence of Solvent and Methanol Substrate}

With regard to water-insoluble lipidic substrates and considering the catalytic performance of lipases in the synthesis direction, the solvation of substrate with the use of an organic solvent is of great importance. The large differences between the physicochemical properties of the organic solvents used in these types of experiments show the necessity of applying a simple basis for solvent selection. The Hildebrand concept, developed based on the vaporization enthalpy change of the solvent and the solvent molar volume (the solubility index $\delta$ ), has been used to evaluate the effects of 28 organic solvents in the enzymatic production of biodiesel (Fu and Vasudevan, 2009). The logarithm of the partition coefficient (log $P)$ also has been used to classify solvents, and the findings of $\mathrm{Fu}$ and Vasudevan (2009) showed that there is no clear-cut correlation between $\log P, \delta$, and the yield of biodiesel produced. Hydrophobic interactions, polarity, and hydrogen bonding forces that are present between atoms and molecules of a particular substance have been used as the basis for developing an index called the Hansen solubility parameter (HSP) (Hansen, 2000). Based on this concept, $n$ hexane, which possesses only hydrophobic characteristics, was selected as the solvent in the present study. The appropriateness of using $n$-hexane in transesterification reactions has also been confirmed by the Vasudevan group for the enzymatic synthesis of biodiesel (Gagnon and Vasudevan, 2011).

Figure 3 shows the trend of methyl oleate production in the present study. In the solvent-free system, equilibrium was established within $48 \mathrm{~h}$ and the yield was only $30 \%$. In contrast, in the presence of $n$-hexane as the solvent and a hexane:oleic acid ratio of $9: 1(\mathrm{v} / \mathrm{v})$, the amount of methyl oleate produced after $12 \mathrm{~h}$ reached $80 \%$ (Figure 3 ). With hexane as the solvent, the reaction proceeded satisfactorily, as expected, and the results presented here are in agreement with literature findings (Gagnon and Vasudevan, 2011).The esterification reaction in the solvent-free system afforded a lower conversion compared to the reaction in the presence of an organic solvent mainly because of the high viscosity of the reaction environment and the lower solubility of the methanol substrate (Qin et al., 2008). These characteristics greatly limit the enzyme diffusion in the test system; therefore, it is difficult for the substrate molecules to reach the catalytic site of the enzyme.

The optimum amount of $n$-hexane to be used in the methanolysis of oleic acid was also determined by changing the $n$-hexane:oleic acid ratios from 1:1 to $11: 1(\mathrm{v} / \mathrm{v})$. As shown in Figure 4, the maximum methyl oleate yield was obtained at a $9: 1(\mathrm{v} / \mathrm{v})$ ratio of $n$-hexane:oleic acid, corresponding to $0.3 \mathrm{M}$ oleic acid. The enhancing effect of $n$-hexane on the biodiesel yield only occurred up to a certain ratio of solvent to oily substrate, and increasing the amount of hexane further was not beneficial. These results were in agreement with the findings reported by Liu et al. (2011), who used isooctane as the solvent; the hydrophobic characteristics of isooctane are similar to those of $n$-hexane (Hansen, 2000).

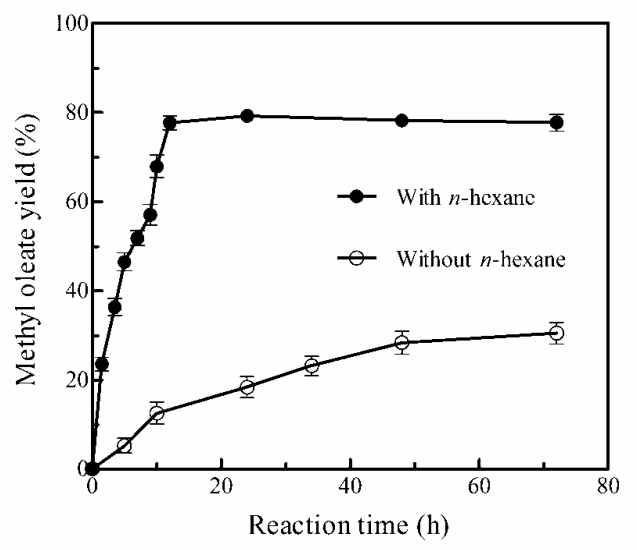

Figure 3: Effect of $n$-hexane as the solvent on the methyl oleate yield. The following experimental conditions were used: molar ratio of methanol:oleic acid, 1:1; number of LIC pieces, 2; incubation temperature, $30^{\circ} \mathrm{C}$; and agitation rate, $150 \mathrm{rpm}$.

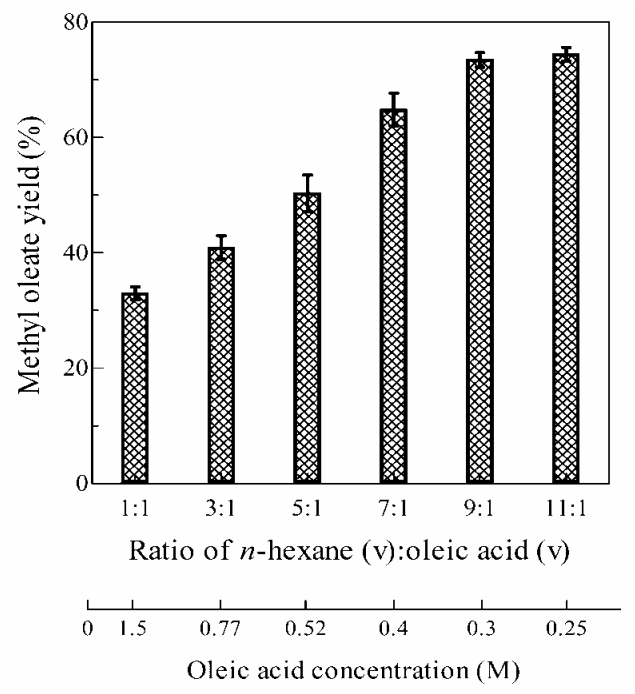

Figure 4: Different ratios (v:v) of hexane:oleic acid affect the methyl oleate yield. The following experimental conditions were used: molar ratio of methanol:oleic acid, 1:1; number of LIC pieces, 2; incubation temperature, $30^{\circ} \mathrm{C}$; and agitation rate, $150 \mathrm{rpm}$. 
The solubility of methanol, a polar substrate (log $P<2$ ), is low in $n$-hexane, meaning that increasing the amount of a solvent with hydrophobic properties is not an effective way to increase the biodiesel yield in the presence of a polar substrate $(\mathrm{Fu}$ and Vasudevan, 2009). The extent of the negative effect due to methanol was decreased through the stepwise addition of this substrate to the reaction medium, as shown in Figure 5. The water trapping behavior of methanol, due to its high capability of forming hydrogen bonds with water molecules, reduces the availability of water, which is essential for the enzymatic activity. The negative effect on the enzymatic activity of water dehydration by a polar substrate is more noticeable in nonaqueous media. In order to reduce the chance of the alcoholic substrate inhibiting the enzymatic activity, in the present study the addition of methanol was carried out in either two or three stages within $24 \mathrm{~h}$ from the beginning of the reaction in the absence of solvent (Figure $5(\mathrm{a}-\mathrm{c})$ ). Using this strategy, the final yield increased considerably $(14-22 \%)$, as shown in that figure. Of course, the same increase in the methyl oleate yield was not obtained when the system was examined in the presence of $n$-hexane (Figure $5(\mathrm{~d}-\mathrm{f})$ ). Thus, the test system response to stepwise methanol addition in the absence of hexane was more favorable. The findings of the present study were in agreement with those reported elsewhere (Shimada et al., 1999).

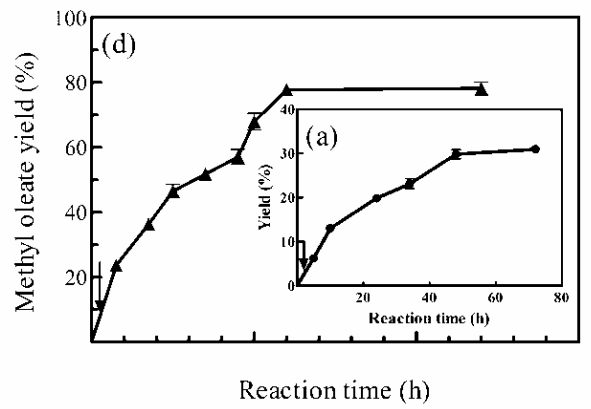

Figure 6 shows the trend of the reaction with three different molar ratios of methanol:oleic acid $(1: 1,1.5: 1$, and $2: 1)$. The highest yield of methyl oleate was obtained with a 1:1 molar ratio of the two substrates. The yields decreased from approximately $78 \%$ to approximately $58 \%$ and $46 \%$ when the methanol: oleic acid ratios were increased to $1.5: 1$ and 2:1, respectively. The undesirable influence of the methanol substrate on the methyl oleate yield was less pronounced when equimolar concentrations of methanol and oleic acid were used.

\section{Effect of Molecular Sieve Addition}

Water is essential for the structural integrity of proteins, including enzymes. Besides this crucial role in living cells, water is the substrate in enzyme-catalysed hydrolytic reactions. For lipase functionality in nonaqueous media, a minimum amount of water is required, where the water activity $\left(\mathrm{a}_{\mathrm{w}}\right)$ used in these environments indicates the extent of bound water in the test system. For instance, the yield of the enzymatic methanolysis of rapeseed oil was the highest at $\mathrm{a}_{\mathrm{w}}=0.55$, and a substantial decrease in the yield was observed at higher values of $\mathrm{a}_{\mathrm{w}}$ (Antczak et al., 2009). In lipase studies such as methanolysis reactions, it is common practice to control a system's water content by using an appropriate adsorbent responsive to the water produced in the test system.
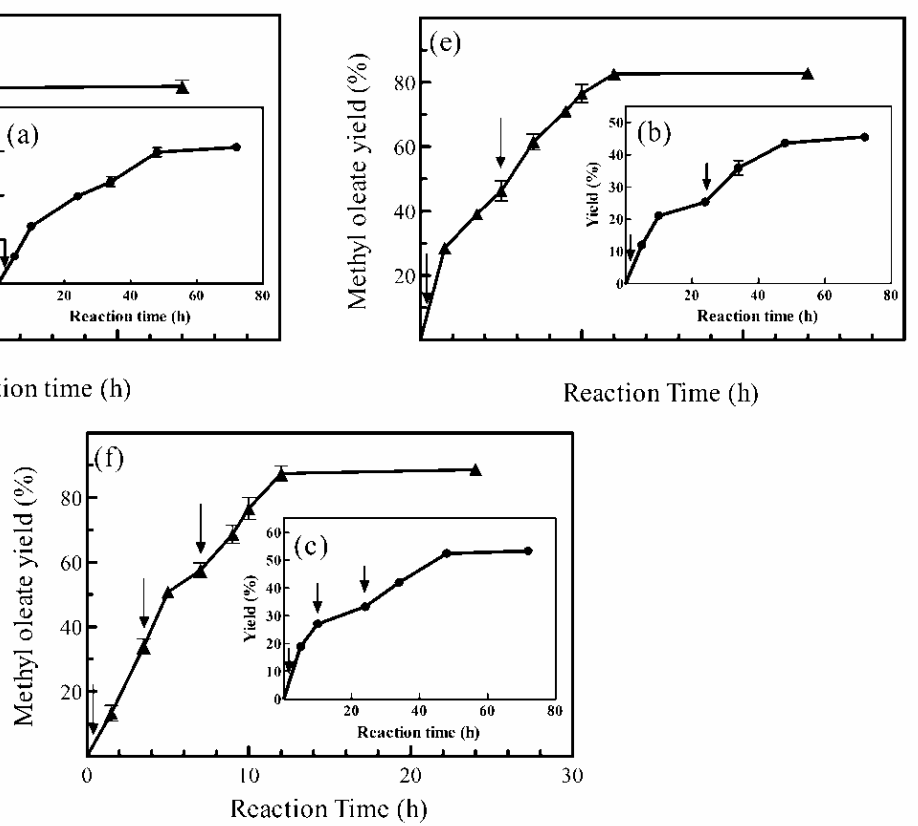

Figure 5: Effect of the stepwise addition of methanol on the methyl oleate yield in the solvent-free systems (a, b, and c) and in the test systems with $n$-hexane as the solvent (d, e, and f). The following experimental conditions were used: molar ratio of methanol:oleic acid, 1:1; number of LIC pieces, 2; incubation temperature, $30{ }^{\circ} \mathrm{C}$; and agitation rate, $150 \mathrm{rpm}$. The arrows indicate the times of methanol addition. 
Figure 7 shows the results of using different amounts of molecular sieves ( $3 \AA$ ). The use of a 10fold excess of molecular sieves increased the methyl oleate yield from approximately $78 \%$ (no sieves) to $93 \%$. The ester yield did not increase further with more adsorbent.

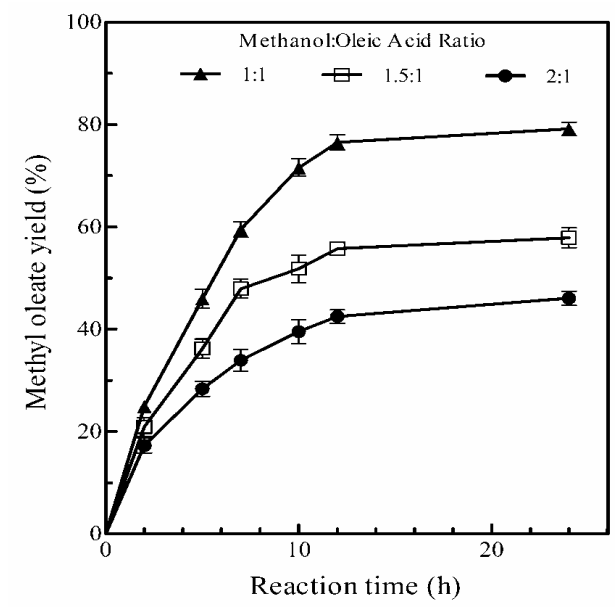

Figure 6: Effect of different concentrations of methanol on the methyl oleate yield. The following experimental conditions were used: number of LIC pieces, 2 ; incubation temperature, $30{ }^{\circ} \mathrm{C}$; agitation rate, 150 $\mathrm{rpm}$; and hexane:oleic acid ratio, 9:1(v/v).

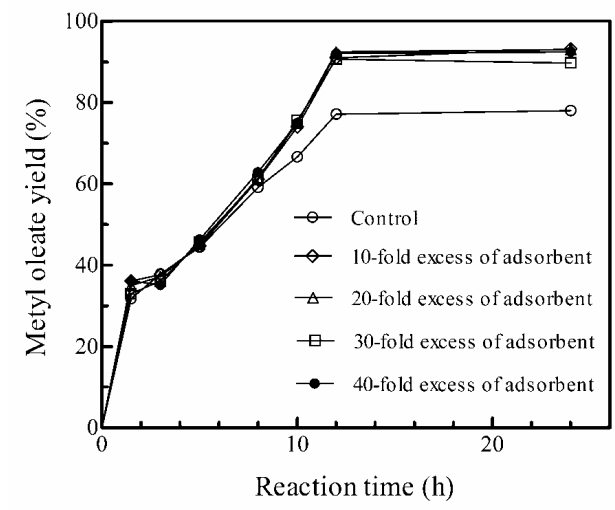

Figure 7: Effect of the amount of adsorbent on the methyl oleate yield. The following experimental conditions were used: molar ratio of methanol:oleic acid, 1:1; number of LIC pieces, 2; incubation temperature, $30^{\circ} \mathrm{C}$; agitation rate, $150 \mathrm{rpm}$; and hexane: oleic acid ratio, 9:1(v/v).

\section{Reusability of the LIC Lipase System}

The extent of enzyme stability depends highly on its structural integrity; moreover, in the case of immobilization, the type of support used in the fixation technique also has a determining role on its threedimensional conformation. The capability of the
LICs to be used repeatedly in the test process was examined in the present study, and the methyl oleate yield in the presence of $n$-hexane remained almost constant at $80 \%$ when the LIC lipase was used for ten process cycles (Figure 8). However, the stability of the LIC lipase in the absence of solvent was not satisfactory, and a considerable decrease in the yield was observed, even after only two cycles (Figure 8). Cellulose, chitin, and glucan are common components of the fungal cell wall. Based on the chemical constituents of the natural fibers, loofa sponge, as a lignocellulosic material, has the capacity to form hydrogen and electrostatic bonds with the surface of fungal cells (Siqueira et al., 2010; Willey et al., 2008). Thus, upon immobilization on loofa, improvement in enzyme/cell stability is expected because of the interactions between the support and the enzyme/cell (Ghamgui et al., 2004). Although these noncovalent bonds are weak, they are economically favorable for further use of the immobilized cells/enzyme. The protective environment provided by the loofa sponge could preserve the functionality of the lipases from $R$. oryzae cells. The role of $n$-hexane as the solvent in the present study was reasonably positive, i.e., the inhibitory action of the methanol substrate on the lipase was more pronounced in the solvent-free system (Li et al., 2008).

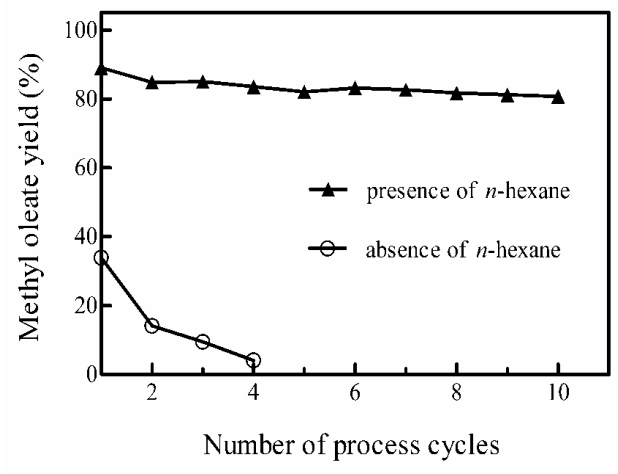

Figure 8: Effect of $n$-hexane on the stability of LIC lipase during the repeated use of LIC pieces in the test system. The following experimental conditions were used: molar ratio of methanol:oleic acid, 1:1; number of LIC pieces, 2 ; incubation temperature, $30^{\circ} \mathrm{C}$; and agitation rate, $150 \mathrm{rpm}$.

\section{CONCLUSION}

- $R$. oryzae as the lipase producer immobilized on loofa sponge was used as the whole cell biocatalyst and biodiesel production was studied using oleic acid as the model substrate in $n$-hexane. 
- The whole-cell biocatalyst consisting of cellbound lipases expressed both hydrolytic and esterification activities; these activities increased upon cell immobilization and the decreasing trend of lipase released to the culture medium was indicative of loofa's positive role in the cell immobilization.

- The negative effect of the water produced during the test process was reduced by using an appropriate molecular adsorbent ( $3 \AA$ molecular sieves).

- The solvent-free system was less capable of protecting the lipases from the inhibitory function of the alcoholic substrate, and the methyl oleate yield decreased by more than $50 \%$.

- The reusability of the LIC lipases in the production of methyl oleate was demonstrated.

- Using this environmentally friendly approach, enzymatic production of biodiesel would be possible in a cost-effective manner. However, the study of the kinetics of enzyme-catalyzed reactions is an indispensable part of biocatalysis and mass transfer resistances play critical roles in these types of reactions. To obtain the whole picture, more work is needed and additional research with respect to LICs is under way in our laboratory.

\section{REFERENCES}

Al-Zuhair, S., The effect of substrate concentrations on the production of biodiesel by lipase-catalyzed transesterification of vegetable oils. Journal of Chemical Technology and Biotechnology, 81, 299-305 (2006).

Andreani, L. and Rocha, J. D., Use of ionic liquids in biodiesel production: A review. Brazilian Journal of Chemical Engineering, 29, 1-13 (2012).

Antczak, M. S., Kubiak, A., Antczak, T., Bielecki, S., Enzymatic biodiesel synthesis-Key factors affecting efficiency of the process. Renewable Energy, 34, 1185-1194 (2009).

Atkinson, B., Black, G. M., Lewis, P. J. S., Pinches, A., Biological particles of given size, shape, and density for use in biological reactor. Biotechnology Bioengineering, 21, 193-200 (1979).

Bajaj, A., Lohan, P., Jha, P. N., Mehrotra, R., Biodiesel production through lipase catalyzed transesterification: An overview. Journal of Molecular Catalysis B: Enzymatic, 62, 9-14 (2010).

Fjerbaek, L., Christensen, K. V., Norddahl, B., A Review of the current state of biodiesel production using enzymatic transesterification. Biotechnology and Bioengineering, 102, 1298-1315 (2009).

$\mathrm{Fu}$, B. and Vasudevan, P. T., Effect of organic solvents on enzyme-catalyzed synthesis of biodiesel. Energy and Fuels, 23, 4105-4111 (2009).
Fukuda, H., Kondo, A., Noda, H., Biodiesel fuel production by transesterification of oils. Journal of Bioscience and Bioengineering, 92, 405-416 (2001).

Fukuda, H., Hama, S., Tamalampudi, S., Noda, H., Whole-cell biocatalysts for biodiesel fuel production. Trends in Biotechnology, 26, 668-673 (2008).

Gagnon, M. D. and Vasudevan, P. T., Effects of solvent and enzyme source on transesterification activity. Energy and Fuels, 25, 4669-4674 (2011).

Ghamgui, H., Chaâbouni, M. K., Gargouri, Y., 1Butyl oleate synthesis by immobilized lipase from Rhizopus oryzae: A comparative study between $n$-hexane and solvent-free system. Enzyme and Microbial Technology, 35, 335-363 (2004).

Hama, S., Tamalampudi, S., Fukumizu, T., Miura, K., Yamaji, H., Kondo, A., Fukuda, H., Lipase localization in Rhizopus oryzae cells immobilized within biomass support particles for use as wholecell biocatalysts in biodiesel-fuel production. Journal of Bioscience and Bioengineering, 102, 328-333 (2006).

Hansen, C. M., Hansen Solubility Parameters: A User's Handbook. CRC Press, Boca Raton, Florida (2000).

Jin, G., Bierma, T. J., Hamaker, C. G., Mucha, R., Schola, V., Stewart, J., Wade, C., Use of a wholecell biocatalyst to produce biodiesel in a watercontaining system. Journal of Environmental Science and Health. Part A, Toxic/Hazardous Substances and Environmental Engineering, 44, 2128 (2009).

Jones, C. L., Lonergan, G. T., Mainwaring, D. E., The use of image analysis for spore counts of white-rot fungi. Biotechnology Techniques, 6, 417-422 (1992).

Kwon, D. Y. and Rhee, J. S., A simple and rapid colorimetric method for determination of free fatty acids for lipase assay. Journal of the American Oil Chemists' Society, 63, 89-92 (1986).

Li, W., Du, W., Liu, D., Rhizopus oryzae Whole-cellcatalyzed biodiesel production from oleic acid in tert-butanol medium. Energy and Fuels, 22, 155158 (2008).

Liu, Y. K., Seki, M., Tanaka, H., Furusaki, S., Characteristics of loofa (Luffa cylindrica) sponge as a carrier for plant cell immobilization. Journal of Fermentation and Bioengineering, 85, 416-421 (1998).

Liu, Y., Liu, T., Wang, X., Xu, L., Yan, Y., Biodiesel synthesis catalyzed by Burkholderia cenocepacia lipase supported on macroporous resin NKA in solvent-free and isooctane systems. Energy and Fuels, 25, 1206-1212 (2011).

Lowry, R. R. and Tinsley, I. J., Rapid colorimetric determination of free fatty acids. Journal of the American Oil Chemists' Society, 53, 470-472 (1976). 
Ogbonna, J. C., Liu, Y. C., Liu, Y. K., Tanaka, H., Loofa (Luffa cylindrica) Sponge as a carrier for microbial cell immobilization. Journal of Fermentation and Bioengineering, 78, 437-442 (1994).

Qin H. E, Yan, X. U., Yun T., Dong W., Biodiesel production catalyzed by whole-cell lipase from Rhizopus chinensis. Chinese Journal of Catalysis, 29, 41-46 (2008).

Rehm, S., Trodler, P., Pleiss, J., Solvent-induced lid opening in lipases: A molecular dynamics study. Protein Science, 19, 2122-2130 (2010).

Saeed, A. and Iqbal, M., Loofa (Luffa cylindrica) sponge: Review of development of the biomatrix as a tool for biotechnological applications. AlChE Journal, 29, 573-600 (2013).

Schmid, R. D. and Verger, R., Lipases: Interfacial Enzymes with Attractive Applications. Angewandte Chemie International Edition, 37, 1608-1633 (1998).

Silva, G. A. M., Da Rós, P. C. M., Souza, L. T. A., Costa, A. P. O., de Castro, H. F., Physico-chemical, spectroscopical and thermal characterization of biodiesel obtained by enzymatic route as a tool to select the most efficient immobilized lipase. Brazilian Journal of Chemical Engineering, 29, 39-47 (2012).

Siqueira, G., Bras, J., Dufresne, A., Luffa cylindrica as a lignocellulosic source of fiber, microfibrillated cellulose, and cellulose nanocrystals. BioResoures, 5, 727-740 (2010).

Shimada, Y., Watanabe, Y., Samukawa, T., Sugihara, A., Noda, H., Fukuda, H., Tominaga, Y., Conversion of vegetable oil to biodiesel using immobilized Candida antarctica lipase. Journal of the American Oil Chemists' Society, 76, 789793 (1999).

Willey, J. M., Sherwood, L. M., Woolverton, C. J., Prescott, Harley, and Klein's Microbiology. 7th Ed., McGraw-Hill, New York (2008).

Zhang, Y., Dubé, M. A., McLean, D. D., Kates, M., Biodiesel production from waste cooking oil: 1 . Process design and technological assessment. Bioresource Technology, 89, 1-16 (2003). 